\title{
Angiopoietin 1 Measurement
}

National Cancer Institute

\section{Source}

National Cancer Institute. Angiopoietin 1 Measurement. NCI Thesaurus. Code C111128.

A measurement of angiopoietin 1 present in a sample. 